\title{
The Impact of on-the-Job Training on Employee Performance:
}

\section{The Case of Riley's Hotel}

\author{
Salini Bafaneli ${ }^{1 *} \&$ Gosekwang Setibi ${ }^{2}$ \\ ${ }^{1}$ Independent Researcher, Gaborone, Botswana \\ ${ }^{2}$ University of Botswana, Department of Management, Gaborone, Botswana \\ *Salini Bafaneli, E-mail: salinibafaneli@gmail.com
}

\begin{abstract}
The main objective of this study was to investigate the impact of on-the-job training on employee performance. It was a case study conducted at Riley's Hotel at Maun; a tourist destination in the North Western part of Botswana. The researchers used a questionnaire to collect data. The results of the study indicated that to a large extent Riley's Hotel implemented on the job training and that the majority of employees have attended the training. There is also an indication that most of the employees believe that on the job training makes them effective in their jobs. Too much work and time constraints were revealed as challenges to the successful implementation of on the job training. Employment of trained staff was suggested as a major possible solution to the challenges of on the job training. The study concludes that even though on the job training was implemented at Riley's Hotel there were a number of challenges militating against its perfect implementation. This study would benefit any organization interested in on-the-job training and employee performance.
\end{abstract}

\section{Keywords}

on-the-job training, employee performance, time-constraints, development, human resources, service delivery, implementation

\section{Introduction}

The world over, developing countries are increasingly concerned with the rapidly changing demand for skills and the slow response of the general and vocational schooling tracks to adjust the provision of skills. As a consequence, many employers complain about the lack of skills and education of their workforce. Policymakers are thus increasingly concerned that the supply of skills in the labour market does not keep pace with the demand. The investment by organizations in on-the-job training is one important way to mitigate this skills' gap as it develops job relevant skills among the existing employees (http://www.izajold.com/content/3/1/19).

Employee performance is critical to the success of organizations and countries alike. It is argued that the most important factor of employee performance is training as it enhances the capabilities of employees (Khan et al., 2011). Therefore, the purpose of this study is to investigate the impact of 
on-the-job training on employee performance at Riley's Hotel. Its objectives are: to find out if on-the-job training is implemented at Riley's Hotel; whether on-the-job-training helps employees to be more effective in their jobs; challenges faced by Riley's Hotel in its attempt to implement on-the-job training and possible solutions to the challenges faced by Riley's Hotel in its implementation of on-the-job training.

\subsection{Background of the Study}

Riley's Hotel is the oldest hotel in Maun. As one crosses the new causeway across the Thamalakane River to the main commercial centre, the Best Western Riley's Hotel is set on the river bank to the left of the main traffic circle. This fine hotel is a very popular stop over with tourists travelling into and out of the delta and has been an important landmark in the town since the 1920s when Charles "Harry" de Beauvior Riley first arrived. In those days it was a grueling 35-hour haul from Francistown to Maun and when the men (mostly professional hunters) arrived, all they wanted was something cold to drink and relax. Seeing the opportunity, Harry set up a little bar that was the scene of many wild parties. Riley's Hotel is part of CrestaMarakanelo which is now the largest Hotel Group in Botswana having begun operation in 1979 (http://www.Cresta-hospitality.com). Riley's Hotel Has a training policy contained in CrestaMarakanelo Group Human Resources Manual, which is aimed at providing direction for timely planning and promoting culture of training.

According to Noe (2005) on-the-job training refers to new or inexperienced employees learning through observing peers or managers performing the job and trying to imitate their behavior. He further posits that on-the-job training can be useful for training newly hired employees, upgrading experienced employees' skills when technology is introduced, cross-training employees within a department or work unit, and orienting transferred or promoted employees to their new jobs. On-the-job training takes various forms, including apprenticeship and self-directed learning programmes. It is an attractive training method because, compared to the other methods, it needs less investment in time or money for materials, trainer's salary, or instructional design.

According to Bocodol (2008) when on the job training was introduced its aim was to change the knowledge, attitude, skills and behavior patterns of the workers in relation to the performance of a given task or organizational goals. The publication also mentions that on the job training is not a new concept as it was used during the era of industrial revolution. It further argued that in Botswana on the job training is not thoroughly practiced as it is the case in developed countries such as the United States, Japan and China possibly because of the fact that the training is time consuming as it calls for one to one interaction between the trainer and the employee. It posits that: Many organizations do not regard on the job training as a professional activity and in many cases training officers are not themselves trained. Some organizations simply ignore on the job training and treat their diverse workforce as if it were homogenous.

The results of the above scenario are usually reflected by poor performance of individual workers as well as the organization, something which works against Botswana's vision 2016's aim of " $A$ 
prosperous, productive andinnovative nation". On-the-job training is an extremely prominent feature on employee performance and service quality provision. Although much has been documented about it and the various forms it takes, it has not received the attention it deserves. It is against this background that the study intends to find out the extent to which on the job training influences employee performance.

\subsection{Research or Specific Objectives}

The objectives of this research study are:

(1) To find out if on-the-job training is implemented at Riley's Hotel;

(2) To find out whether on-the-job training helps employees to be more effective in their jobs;

(3) To find out the challenges faced by Riley's Hotel in its attempt to implement on the job training;

(4) To find out possible solutions to the challenges faced by Riley's Hotel in its implementation of on the job training.

\subsection{Research Questions}

(1) Does Riley's Hotel implement on the job training?

(2) Does on the job training contribute to employee performance?

(3) What challenges exist on the implementation of on the job training?

(4) What action can be taken by both management and staff to address the challenges?

\subsection{Significance of the Study}

It is hoped that the study would provide information that can be useful to all managers in line with the implementation of on-the-job training. It intends to help them to find effective ways of developing and implementing on-the-job training. It is envisaged that Human Resources training institutions will find this study very useful in the development of their future training programmes. The study will add knowledge to the subject area and will trigger more research around the subject. Policy makers, business community, Human Resources students and Human Resources personnel will find this study useful in their pursuit to meet the demands of vision 2016 which intends to build an educated and informed nation. As a result of perusing through this project other organizations may decide to benchmark on the process of on-the-job training at Riley's hotel.

\subsection{Problem Statement}

Having been regular customers at Riley's Hotel, the researchers have observed failure by some employees to provide quality service to customers. It is of paramount importance for Riley's Hotel to provide quality service in order to satisfy its customers. Failure to do so would lead to the hotel losing customers and thus failure to meet its financial objectives. Interestingly Riley's Hotel is situated proximally to the Okavango Delta, a tourist attraction of repute. It is therefore critical for Riley's Hotel to provide quality service to its varied clientele. This led to a decision to investigate the extent to which Riley's Hotel implements on-the-job training and its impacts on service delivery by employees. On-the-job training is credited for enhancing individual productivity and improvement of job performance in the work environment (Alipour et al., 2009).

Published by SCHOLINK INC. 


\subsection{Definitions of Operational Terms}

Training is the acquisition of knowledge, skills, and competencies as a result of the teaching of vocational or practical skills and knowledge that relate to specific useful competences.

On-the-job training an activity undertaken at the workplace which is designed to improve an individual's skills or knowledge.

Job Rotationis when employees are transferred from job to job on a systematic basis.

Coachingis when a colleague, co-worker or manager who works with an employee motivates him or her, helps her develop skills and provides continuous feedback on his or her progress.

Apprenticeship refers to learning from a more experienced employee or employees for a specified duration of time.

Vision 2016 refers to the long-term vision for Botswana.

\subsection{Literature Review}

According to Kleynhans et al. (2007) on-the-job training is when the employee's supervisor or an experienced co-worker teaches the employee about the job while she is actually working. He argues that the majority of training and development occurs on the job training and that it is very effective. The researchers share the above sentiments as learning by doing is a reliable educational technique. According to Bocodol (2008) a survey that was carried in the UK revealed that about half of the training delivered across all industries and sectors happens through on the job training. The study concluded that on the job training was the most popular method of training and over half of the respondents reported that they found it to be the best method. It further revealed that learners prefer active rather than passive learning. The above findings demonstrate that on-the-job training is the most effective training method as it gives immediate feedback to both trainers and trainees.

http://www.cipd.co.uk/otjtrain.htm posits that the largest survey ever undertaken in the UK indicated that about half of the total training delivered across all industries and sectors, consisted of on the job training and that on the job training was the most preferred method of learning. According to the website: $46 \%$ of the respondents of the most recent surveys indicated being shown how to do things then practicing them as their best method. Virtually identical results were recorded in the 2002, 2005 and 2008 surveys.

The above quotation emphasizes the importance of learning by doing as compared to theoretical acquisition of knowledge which does not give immediate feedback on the performance of the trainees nor does it equip them with experience. On the contrary, Van der Klink and Streumer (2002) argued that on-the-job training programmes were only partially successful in realising training goals. They indicate that self-efficacy, prior experience with tasks, managerial support and work load were the most powerful predictors for training effectiveness. They suggest that on-the-job training is not entirely an effective training method. Despite the above arguments, on-the-job training has more advantages than other available training methods as it does not take the employee away from their working environment. In addition on-the-job training is a cost effective way that helps employees gain knowledge about the 
latest development in their industry. It can also lead to promulgation of new ideas within an organization (http://www.economictimes.com).

It is argued that the purpose of the on-the-job training session is to provide employees with task-specific knowledge and skills in their work area. That is, the knowledge and skills presented during on-the-job training are directly related to job requirements (Alipour et al., 2009). It can therefore be deduced that on-the-job training is workplace friendly in that it improves the expertise of the job holders thus making them confident in the performance of their duties. This would lead to customer satisfaction and customer loyalty. http://www.izajold.com/content/3/1/19 posits that skills shortages and skill mismatch are a pressing concern for policymakers in several developing countries. Therefore providing on-the-job training can be an effective policy tool to shape the skills of the existent workforce to the specific needs of the firms.

CrestaMarakanelo Hotel Group training policy stipulates that on the job training is the responsibility of the section head. This type of training is scheduled with and conducted by an in-house "Field Expert". Various methods are generally used for on-the-job training and development and this include coaching, job rotation, understudy, acting appointments and delegation. Clear objectives and desired outcomes expected at the end of the training programme have to be established and followed up, with implementation of corrective measures where necessary. According to the group's policy on the job training can be done as follows:

(1) Trainees can be placed in other hotels (internationally and locally) when a need arises and with arrangement and approval by management.

(2) All localization programmes are to be preceded by a fully-fledged and evaluable on the job training programme.

(3) Informal on the job training is worked out between the employees. Though it is not necessarily planned and has no definite time frame with no measurable results expected, it has to be encouraged. It may take the form of shadowing, mentoring, reading assignments or work assignments. It is the responsibility of the supervisor or manager to provide accurate and current information.

The policy also states that evaluation of training should be done and must be based on the following criteria:

(1) Participant reaction to the training programme;

(2) Extent of learning (skills acquired, knowledge, changed attitudes);

(3) Behavioural changes;

(4) Work results.

On-the-job training has been subject to different concerns. While it has been used more often than off-the-job training, in most instances it is informal, which means that it occurs without advance planning or involvement by management. The entire training may be placed in the hands of an individual who does not know the work, has poor work habits, or considers the training as an imposition on his or her work time. Under these conditions, training takes lower priority than work, 
even though training might help improve the quality of the work (Jacobs, 2003).

Most of on-the-job training programmes can be considered unplanned or, as described by Swanson and Swazin (1975), unstructured in nature. According to Jacobs (2003) unstructured on-the-job training takes place when trainers learn job knowledge and skills from explanations or demonstrations by others, through trial and error efforts, self-motivated reading or questioning on their own, or simply imitating the behaviours of others. A newly hired nurse is quoted by Jacobs (2003) as having said: when I first came on, I was trained by another nurse at the time. We became friends, more or less. I relied upon her to tell me what to do. She told me, do this and don't do that. This is how to do this. Eventually I learned what she wanted me to learn, but I found that I could learn just as well on my own. I am not sure if ideally learned what they wanted me to learn. Anyway after a while, I just started figuring out things on my own.

The above comments of a newly hired nurse who received unstructured on-the-job training may be representative of most employees who receive unstructured on-the-job training. Jacobs (2003) argues that unstructured on-the-job training has a number of problems and are as follows:

(1) The desired training outcomes are rarely, if ever achieved, and when it is, all trainees rarely achieve the same outcomes.

(2) The training content is often inaccurate or incomplete, or else it represents an accumulation of bad habits, misinformation. And possibly unsafe shortcuts on which employees have come to rely overtime.

(3) Experienced employees are seldom able to communicate what they know in a way that others can understand.

(4) Experienced employees use different methods each time they conduct the training, and not all the methods are equally effective.

(5) Employees are often unsure whether they are even allowed to train others, and they may say "it's not my job".

(6) Many employees fear that sharing their knowledge and skills will reduce their own stakes as experts and possibly even threaten their job security.

Bocodol (2008) outlines benefits and challenges of on-the-job training as follows:

a) Benefits

(1) Permits the trainee or employee to learn on the environment of his or her job under the tutelage and close supervision of a tutor who is usually either his or her immediate supervisor or experienced non-supervisory employees;

(2) The employee is carefully guided and observed as he or she carries out work;

(3) The employee is learning while working;

(4) The employee is in a situation in which he or she can actually experience a feeling of achievement as he or she works to produce products or services;

(5) It results in unique incentives during the learning process;

(6) It provides the best training in terms of fitting training clearly to the requirements of the job; 
(7) The danger of the gap between what the trainee is taught in the classroom and actual experience is completely removed or greatly reduced;

(8) The problem of limited transfer of knowledge or skill learned is eliminated;

(9) The skills learned are immediately applicable to the job.

b) Challenges

(1) The training may be given in bits leading to an employee not getting a full picture of the organization;

(2) Too much training can be given in a session leading to information overload and fatigue on the part of the employee;

(3) The trainer may not have sufficient knowledge of the process or expertise in the instructional techniques;

(4) Immediate practice may not be accompanied by feedback and this could result into the employee feeling abandoned after the initial experience;

(5) There is a tendency of fitting on-the-job training when it is convenient for office routine rather than at optimal time.

\section{Method}

This study investigates the impact of on-the-job training on the performance of employees at Riley's Hotel. The choice of the research design to be used in a study should depend on the nature of the research, the possible limitations and the underlying paradigm that informs the research project. Zikmund (2003) stated that there are three basic types of research design, qualitative design, quantitative design and a hybrid between qualitative and quantitative research designs.

Quantitative research method derives empirical generalizations which determine future courses of action or which solve a particular research. According to (Cooper \& Schindler, 2003) the objective of the quantitative research approach is to develop and employ mathematical models, theories. The research findings are then subjected to statistical manipulation to produce broadly representative data that can be extensively applied to the total population.

Qualitative research is an umbrella term covering an array of interpretive techniques that seek to describe, decode, translate and otherwise come to terms with the meaning, not the frequency, of certain more or less naturally occurring phenomena in the social world (Van Maanen, 1983). According to Tustin et al. (2005) a quantitative research generally involves the generation of statistical data from large-scale surveys using methods such as structured interviews and questionnaires in order to generalize the results to a wider setting.

It was therefore appropriate to employ quantitative method because of the characteristics of this approach, which allows for data analyses through statistics and hypotheses testing and allows the generalization of the results to a wider setting (Ghauri \& Gronhaug, 2005). Furthermore, the results obtained through quantitative research are objective and the design is more scientific as compared to 
qualitative research design.

Qualitative research is an umbrella term covering an array of interpretive techniques that seek to describe, decode, translate and otherwise come to terms with the meaning, not the frequency, of certain more or less naturally occurring phenomena in the social world (Van Maanen, 1983). According to Tustin et al. (2005) a quantitative research generally involves the generation of statistical data from large-scale surveys using methods such as structured interviews and questionnaires in order to generalize the results to a wider setting.

Self-administered questionnaires were used to gather information on the views of management and staff concerning the impact of on-the-job training on employee performance at Riley's Hotel. Questionnaires do have open and closed-ended questions. The language used for the instrument is English, but the respondents were allowed to use Setswana whenever they are not comfortable with English.

Riley's Hotel has a population of sixty employees comprising of five who are in the management team and fifty five members of staff. The study targeted at least forty eight respondents which is eighty percent of the total population.

To ensure that each employee had a chance of being selected, simple random sampling was used. In this case, each employee's number was written on a piece of paper and all the pieces of paper were put into a container which was then shaken. The researchers then picked the numbers of employees randomly such that each respondent had an equal chance of being picked.

To collect data, the researchers used a questionnaire. Aself-administered questionnaire was used as a method of data collection since the researchers are fulltime employees and had limited time to use other available methods which could have required more time. Self-administered questionnaire as the name suggests, is filled in the absence of an investigator (Mitchel \& Jolley, 2010). It is further explained that these kind of questionnaires are easily distributed to a large number of people. Self-administered questionnaires are also a cheaper and easier way to get honest answers from a lrge number of people (Cargan, 2007).

The questionnaire was categorised into three sections. Section A contained personal data and questions were closed. Section B also contained closed questions whilst section C contained both open and closed type of questions. The questionnaires asked for employees' perceptions regarding the extent to which on the job training is implemented at Riley's Hotel. Response choices were arranged in a five-part Likert scale ranging from strongly agree (1) to strongly disagree (5). An open- ended section was added to collect qualitative responses by asking respondents to share their feelings and opinions about on the job training.

Before being used for the research, the questionnaires were tested for validity and reliability to determine if they measured what they were intended to establish. Questionnaires were given to the research coach and fellow researchers to asses for validity. Their comments were used to modify the instrument where necessary. To increase reliability, the instrument was piloted before fulltime 
collection of data. Piloting helped the researchers to refine the instrument of data collection.

According to Bless and Higson-Smith (2000) data analysis is conducted so that the researcher can detect consistent patterns within the data, such as the consistent covariance of two or more variables. Qualitative and quantitative methods of data analysis were used to complement each other. Data was analysed by describing the responses of the participants and were also described using statistical data. Tables, graphs and charts were used to analyse data. Conclusions were then drawn from data descriptions and statistical data.

\section{Result and Discussion}

A total of forty eight Riley's Hotel employees responded to the questionnaires, three from management and forty five from other members of staff. Of the 48 employees 18 were males and 30 were female. The figures indicate that there were more female respondents than male respondents. The distribution according to age shows that $12(25 \%)$ of the respondents ranged from $31-45$ years whilst $36(75 \%)$ ranged from 18-30 years. The above figures are an indication that the majority of the respondents range from 18 to 30 years whilst a fewer number ranges between 31 to 45 years.

The respondents had the following qualifications. $22(45.8 \%)$ of the respondents were junior certificate holders, 15 (31.3\%) have Cambridge Overseas School Certificate or Botswana Government Certificate of Secondary Education, six (12.5\%) have certificates, whilst $5(10.4 \%)$ have their first degrees in various categories.

It is important to note that all the degree holders were attached or worked in positions they were trained for. Length of service at Riley's Hotel was also considered. Those who have worked between 0-1 year were 18 (37.5\%), those who have worked for 1-5 years were 20 (41.6\%), those who have worked for 6-10 years were $6(12.5 \%)$ and the remaining $4(8.3 \%)$ have an experience of above 15 years. Statistically it shows that the majority of respondents' length of service at Riley's Hotel ranged from $1-5$ years.

The distribution of the forty eight respondents who comprises of both management and staff is represented in Table 1 below.

Table 1. Frequency Distribution of the Responses on whether on the Job Training is Implemented at Riley's Hotel

\begin{tabular}{lll}
\hline RESPONSE & FREQUENCY & PERCENTAGE (\%) \\
\hline SA & 42 & 87.5 \\
A & 6 & 12.5 \\
U & 0 & 0 \\
D & 0 & 0 \\
SD & 0 & 0 \\
\hline
\end{tabular}


An examination of the above findings in Table 1 show that $87.5 \%$ strongly agree that on the job training is implemented whilst 12.5 agrees that it is implemented. There is an indication that all the respondents are of the opinion that Riley's Hotel is to a larger extent implementing on the job training.

Table 2. Frequency of Attendance

\begin{tabular}{lll}
\hline RESPONSE & FREQUENCY & PERCENTAGE \\
\hline SA & 30 & 62.5 \\
A & 12 & 25 \\
U & 6 & 12.5 \\
D & 0 & 0 \\
SD & 0 & 0 \\
\hline
\end{tabular}

It is clear from Table 2 that $87.5 \%$ of the respondents have attended on the job training at Riley's Hotel, whilst the remaining $12.5 \%$ is uncertain of attendance an indication that they may not be aware of on the job training or that they have not attended altogether.

Table 3. Frequency of Perceived Effectiveness

\begin{tabular}{lll}
\hline RESPONSES & FREQUENCY & PERCENTAGE (\%) \\
\hline SA & 40 & 83.3 \\
A & 4 & 8.3 \\
U & 4 & 8.3 \\
D & 0 & 0 \\
SD & 0 & 0 \\
\hline
\end{tabular}

Table 3 shows that $83.3 \%$ of the respondents Strongly Agree (SA), whilst 8.3\% Agree (A) that on the job training makes them effective in their jobs. The remaining 8.3 are Uncertain (U) of the influence on the job training has on their job effectiveness. Similar observations were made by Jacobs (2003) who pointed out that on-the-job training helps ensure that employees do what the organization asks of them. $\mathrm{He}$ also notes that on-the-job training is ultimately about developing high levels of employee competence or expertise. Miller (1987) also concurs with Jacobs on the issue of the effectiveness of on-the-job training. 
Table 4. Frequency of Perceived Challenges

\begin{tabular}{lll}
\hline CHALLENGES & FREQUENCY & PERCENTAGE \\
\hline Too much work & 20 & 41.7 \\
Time & 10 & 20.8 \\
constraints & & \\
No challenges & 8 & 16.7 \\
\hline
\end{tabular}

$41.7 \%$ of the respondents in Table 4 picked too much work as a challenge whilst $20.8 \%$ picked time constraints as a challenge. This is an indication that there is still room for improvement on the implementation of on the job training at Riley's Hotel. The issue of too much work was raised by Jacobs (2003) who pointed out that under such conditions training takes lower priority than work, even when training might help improve the quality of the work.

Table 5. Suggested Solutions

\begin{tabular}{lll}
\hline SUGGESTED SOLUTIONS & FREQUENCY & PERCENTAGES \\
\hline Employment of trained staff & 23 & 47.9 \\
Training of trainers & 5 & 10.4 \\
Reviewing of training policy & 2 & 4.2 \\
No solutions & 8 & 16.7 \\
\hline
\end{tabular}

Table 5 shows the frequencies and percentages of the suggested solutions to the challenges for the implementation of on-the-job training. $47.9 \%$ of the respondents suggest employment of trained personnel as they would easily benefit from on the job training than those who have not received pre-training. $10.4 \%$ suggested that there should be thorough training of trainers before they can be expected to train other employees. $4.2 \%$ are of the view that the training policy should be reviewed and strengthened for good results. $16.7 \%$ is undecided or neutral. The issue of training of trainers was also raised in Noe (2005).

\subsection{Conclusion and Recommendations}

The study investigated the extent to which on-the-job training impacts on employee performance at Riley's Hotel in Maun. There were forty eight respondents who comprised of management and staff of the hotel. Despite the importance attached to on-the-job training the study revealed some challenges to the implementation of on-the-job training.

The general image portrayed by the findings and the discussions is that on-the-job training is very vital on the effectiveness of the employees. That is it plays an important part in employee performance. The researchers conclude that even though on the job training is implemented at Riley's Hotel there are some challenges which militate against its perfect implementation. 
As a result of the findings and conclusions of this study the researchers recommends that:

(1) All employees should be oriented and made aware of what on-the-job training and its importance is, and when and why they are part of it.

(2) On the-job-training should be structured.

(3) Training policy should be availed to employees so that they know and understand what is expected of them at all times.

(4) Thorough training of trainers should be done.

(5) Riley's Hotel should benchmark on other organizations to strengthen their training policy with reference to on-the-job training.

\section{References}

Baker, T. L. (1999). Doing Social Research. Boston: McGraw Hill.

Barrington, H., \& Reid, M. A. (1994). Training Interventions: Managing Employee Development. London: Institute of Personnel Development.

Bless, C., \& Higson, S. C. (2000). Fundamentals of Social Research Methods. Lusaka: Juta Education (PTY) Ltd.

BOCODOL. (2008). Human Resources Development. Gaborone: BOCODOL and ICGCargan.

L. (2007). Doing Social Research. United States of America: Rowman \& Littlefield Publishers, Inc.

Cohen, L., \& Manion, L. (1994). Research Methods in Education. London: Routledge.

Cooper, D. R., \& Schindler, P. S. (2003). Business Research Methods. New York: McGraw-Hill/Irwin.

Ghauri, P., \& Gronhaug, K. (2005). Research methods in business studies. Dorset: Prentice Hall.

Jacobs, R. L. (2003). Structured on-the-job training: Unleashing Employee Expertise in the Workplace. San Francisco: Berret Koehler Publishers, INC.

Kleynhans et al. (2007) Human Resource Management: Fresh Perspectives. Capetown: David Langman.

Mitchel, M. L., \& Jolley, J. M. (2010). Research Design Explained. United States of America: Macmillan Publishing Solutions.

Noe, R. A. (2003) Employee Training and Development. New York: MC Grow-Hill International.

Republic of Botswana. (1997). Long Term Vision for Botswana (Vision 2016). Gaborone: Government Printer.

Salant, P., \& Dillman, D. (1994). How to Conduct Your Own Survey. New York: John Wiley and Sons, INC.

Tashakkori, A., \& Teddlie, C. (1998). Mixed Methodology: Qualitative and Quantitative Approaches Combining. California: SAGE Publications.

Tustin, M., Lighthelm, G., \& Martins, N. (2005). Marketing Research in Practice. Pretoria: Unisa Press.

Van Maanen, J. (1983). Qualitative Methodology. Beverly Hills: Sage Publications. 
Wilmot, P. F. (1985). Sociology: A New Introduction. London: Collins International Textbooks.

Zikmund, W. (2003). Business Research Methods. Ohio: South-West Publishers.

http:www.cipd.co.uk/ottrain.htm [Accessed 22 April 2015]

http:www.economictimes.com [Accessed 24 April 2015]

http://www.izajold.com/content/3/1/19 [Accessed 24 April 2015]

http://www.cipd.co.uk/otjtrain.htm [Accessed 25 April 2015]

http://www.izajold.com/content/3/1/19 [Accessed 25 April 2015] 